medRxiv preprint doi: https://doi.org/10.1101/2021.03.14.21253555; this version posted March 17, 2021. The copyright holder for this preprint (which was not certified by peer review) is the author/funder, who has granted medRxiv a license to display the preprint in It is made available under a CC-BY-NC-ND 4.0 International license .

\title{
Impact of booster COVID-19 vaccine for Moroccan adults: A discrete age-structured model approach
}

\author{
Aayah Hammoumi ${ }^{\mathrm{a}}$, Hanane Hmarrass ${ }^{\mathrm{b}}$, Redouane Qesmi ${ }^{\mathrm{c}, *}$ \\ ${ }^{a}$ Department of Biology, Cadi Ayyad University, Semlalia, Marrakech 40000, Morocco \\ ${ }^{b}$ Faculty of Sciences and Technologies, Sidi Mohamed Ben Abdellah University, Fez 30000, Morocco \\ ${ }^{c}$ Superior School of Technology, Sidi Mohamed Ben Abdellah University, Fez 30000, Morocco
}

\begin{abstract}
Public health control strategies, such as lockdown, seem to be effective in reducing the spread of the pandemic, but are ineffective as a whole since lockdown is responsible of global economic crisis and badly lived by the majority of children and adults who have developed mental health disorders and familial problems as well. Thus, the development of a vaccine against COVID-19 is needed to control this disease. We have developed a discrete age-structured model and followed the Moroccan vaccination program to assess the impact of booster vaccination targeting Moroccan adults against COVID-19. Using the derived model, we estimated some relevant model parameters related to COVID-19 using collected cumulative mortality and reported Moroccan data. A control reproduction number $R_{c}$, which determines the necessary level of vaccine uptake that lead to COVID-19 eradication is determined. Furthermore, a herd immunity threshold above which the population can be protected from COVID-19 infection is derived. Analyzing the model, sufficient and necessary conditions for the eradication of the disease are obtained as well. Next, we perform numerical simulations to study the impact of several uptake levels of the potential vaccine on the persistence and the extinction of COVID-19 pandemic. Our results show that the COVID-19 is expected to last past 2021 in the absence of a vaccination program. Moreover, a vaccination of the adult population at rate $0.6 \%$ per day needs at least $67 \%$ of vaccine efficacy and $90 \%$ of immunogenicity rate to eradicate the disease. Using Sinopharm vaccine, the herd immunity can be achieved when about half of Moroccan adult population is immunized against the COVID-19. However, using Oxford-Astrazeneca vaccine, less than $60 \%$ of adult population must be immunized against the disease to achieve the herd immunity. Finally, if vaccine efficacy is about $80 \%$ and the immunogenicity is about $50 \%$ then vaccinating adults at rate of $0.6 \%$ per day could protect roughly $22 \%$ of children from COVID-19 infection.
\end{abstract}

\section{Introduction}

The newly emerging coronavirus diseases become constant threats to global public health [50]. There are seven coronaviruses (CoVs) known to infect humans so far [63]. Among them, three have caused more severe respiratory illness and fatalities including SARS-CoV,

* Corresponding author

NOTE: This preprint reports new research that has notbeen certified by peer review and should not be used to guide clinical practice. 
medRxiv preprint doi: https://doi.org/10.1101/2021.03.14.21253555; this version posted March 17, 2021. The copyright holder for this preprint (which was not certified by peer review) is the author/funder, who has granted medRxiv a license to display the preprint in It is made available under a CC-BY-NC-ND 4.0 International license .

MERS-CoV and SARS-CoV-2 [50]. Over the two past decades, they were responsible for three major coronaviruses outbreaks. Indeed, in November 2002, the first case of severe acute respiratory syndrome (SARS) emerged in Guangdong, China. The disease has reached pandemic by July 2003 and mysteriously disappeared in the same year with a total of 8,096 reported cases, including 774 deaths in 27 countries [43. Ten years later, the Middle East respiratory syndrome (MERS) emerged in Saudi Arabia and caused an epidemic in the Middle East. Between April 2012 and December 2019, there have been 2499 confirmed cases of MERS and 858 deaths in 27 countries [23, 35]. The most severe acute respiratory syndrome coronavirus 2 (SARS-CoV-2) is the last coronaviruses which probably emerged in China in December 2019 and continues to progress to date [18, 56]. Although less lethal than SARS and MERS, SARS-CoV-2 is more transmissible and, the so-called COVID-19 disease, reached a pandemic status in mid-March 2020 [50, 18, 10]. Affecting 218 countries and territories around the world, it is responsible actually of more than 61 million cases of infection and 1.4 million deaths globally. Furthermore, despite the public health measures taken to control the disease spread, the world is facing an unprecedented economic crisis and the vaccination becomes the only hope to eradicate the COVID-19 and to allow people to return to normal life [39]. An effective COVID-19 vaccine must provide a strong and long term protective antibody response [11]. Unfortunately, until the end of 2020, there were no vaccine approved against any Human coronaviruses. In the past, several vaccine candidates for SARS and MERS have been under development but the research program has been shelved because of three reasons [2, 13]. First of all, the natural extinction of SARS-CoV occurred before the process of vaccine development was completed. Secondly, there was no enough financial support for vaccine development, and, finally, the market size deemed to be too small by the large pharmaceutical companies [56, 6]. However, due to the great genetic similarity between SARS-CoV and SARS-CoV-2, the acquired knowledge is now very useful for COVID-19 vaccine development [55]. Different technology platforms are performed including both traditional (i.e. inactivated virus, live attenuated virus and protein/adjuvant) and novel approaches (i.e. viral vectors and nucleic acids) [29, 52, 47]. Furthermore, supported by WHO and partners, several pharmaceutical companies and academic institutions worldwide joined their effort to produce a safe and effective vaccine as soon as possible in early 2021 [47, 59, 64]. This constitutes a real challenge as vaccine development process takes more than a decade [15]. In the case of SARS-CoV-2, the internationally race for COVID-19 vaccines started shortly after first sequencing of its complete genome by China in January, 2020 [22]. Currently, at least 151 vaccine candidates are in preclinical evaluation, and about 48 are in clinical evaluation for which a dozen are available or nearing the final stage of testing [60, 37, 47]. Once approved, the WHO and partners will guarantee access to these vaccines worldwide though the COVAX program in order to cover 20 of the world's population [60, 61]. Health workers and vulnerable people will be prioritized. Additional doses of vaccine may be provided if the epidemiological situation of country so requires [61. Morocco is one of the countries hitted by COVID-19 with a total of 428193 confirmed cases and 7170 deaths as of December 26th; 2020; 48. The Moroccan government decided then 
medRxiv preprint doi: https://doi.org/10.1101/2021.03.14.21253555; this version posted March 17, 2021. The copyright holder for this preprint (which was not certified by peer review) is the author/funder, who has granted medRxiv a license to display the preprint in It is made available under a CC-BY-NC-ND 4.0 International license .

to be among the countries to conduct a mass emergency vaccination campaign against the COVID-19. Since the end of December 2020, the Moroccan Kingdom intends to launch an emergency vaccination program for the adult population upon immediate receipt of the first pre-ordered doses of vaccines from the Sinopharm or Astrazeneca companies. It will cover $80 \%$ of the population aged over 18 years old. The program will be conducted over a period of 12 weeks in which people will receive two doses of vaccine separated by 21 days in average.

Mathematical modeling has proven to be a powerful tool to predict the dynamics of the epidemic and to help decision makers to evaluate the effectiveness of public health control interventions (See [31, 38, 53, 19] and references therein). Furthermore, mathematical models can be used to assess whether a vaccination strategy will be effective in eradicating or controlling a disease. Using a mathematical model of COVID-19 vaccine portfolio in [34, McDonnell et al. estimated timelines and probabilities of success of COVID-19 vaccines. Their results suggests that, by the end of April 2021, there is a $50 \%$ of chance that a safe and efficient vaccine can be approved by the end of 2021. Furthermore, it could take more than a year to produce sufficient vaccines to cover 50 million medical staff in the entire world. In [26, Peter Jentsch et al. developed an age-structured SEAIR model of COVID-19 with vaccination in Ontario to check whether it is better to vaccinate the most vulnerable individuals or those who spread the virus further to others. They found that using vaccines to break the spread could minimize mortality impressively than using the vaccines selecting elderly people. Tom Britton et al. in [7] developed an age-structured mathematical model according to social activity level. They estimated that if the basic reproduction number reaches 2.5, then the disease-induced herd immunity level could reach $43 \%$, which is lower than the classical herd immunity level. Mukandavire et al. used a mathematical model fitted to COVID-19 daily new cases in South Africa to estimate the critical vaccination coverage that control the disease for different vaccine efficacy levels. They estimated that a vaccine with 70\% efficacy can eradicate COVID-19 disease in south Africa [36]. In [17, Enahoro A. et al. used of a mathematical model to evaluate the effect of an imperfect COVID-19 vaccine on the eradication of COVID-19 disease in the United States. Their study suggests that the likelihood of COVID-19 eradication in the United States can be highly improved if the vaccination is accompanied with non pharmaceutical measures.

In this work, we develop a discrete age-structured model with a booster vaccination, focusing on an established path of COVID-19 transmission from children to adults and vice versa. In other words, we present a model, splitting the population into two different cohorts, to focus our investigation on a vaccination program targeting adults aged over 18 years. Since the developed COVID-19 vaccine may not always hold when carried out to the patient and doesn't always protect against infection [21, 27], our model will include varying efficacies and immunogenecities of the vaccine against COVID-19. The model is a useful tool, which will be used to assess the vaccination rate, efficacy and the immunogenicity of vaccine needed to eradicate the COVID-19 according to the intended strategy followed by the Moroccan Government. 
medRxiv preprint doi: $h t t p s: / / d o i . o r g / 10.1101 / 2021.03 .14 .21253555$; this version posted March 17, 2021. The copyright holder for this preprint (which was not certified by peer review) is the author/funder, who has granted medRxiv a license to display the preprint in It is made available under a CC-BY-NC-ND 4.0 International license .

\section{Method}

\subsection{Data collection}

The data of reported symptomatic infectious and death cases is collected each day at $11 \mathrm{pm}$ from the official Coronavirus Portal of Morocco [48]. Data information, as shown in Fig. 2.2 and Fig. 2.1 covers the cumulative number of reported cases and death cases from March 2nd to December 26th, 2020.
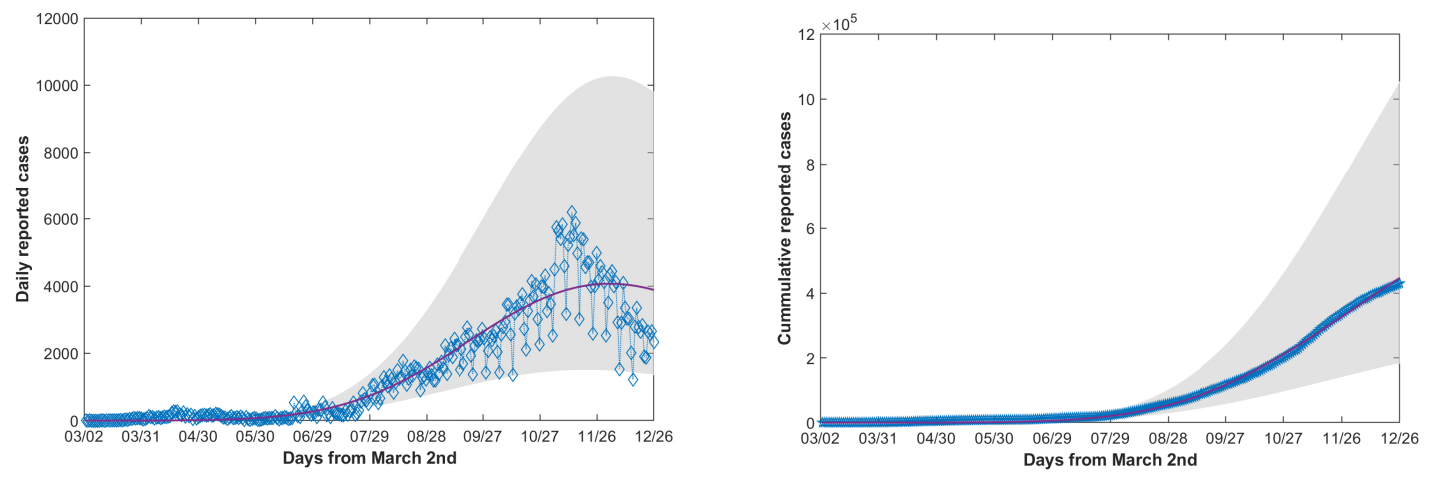

Figure 2.1: COVID-19 epidemic data and fitting results in Morocco using model 2.1 in the absence of vaccination between March 2nd, 2020 and December 26th, 2020.
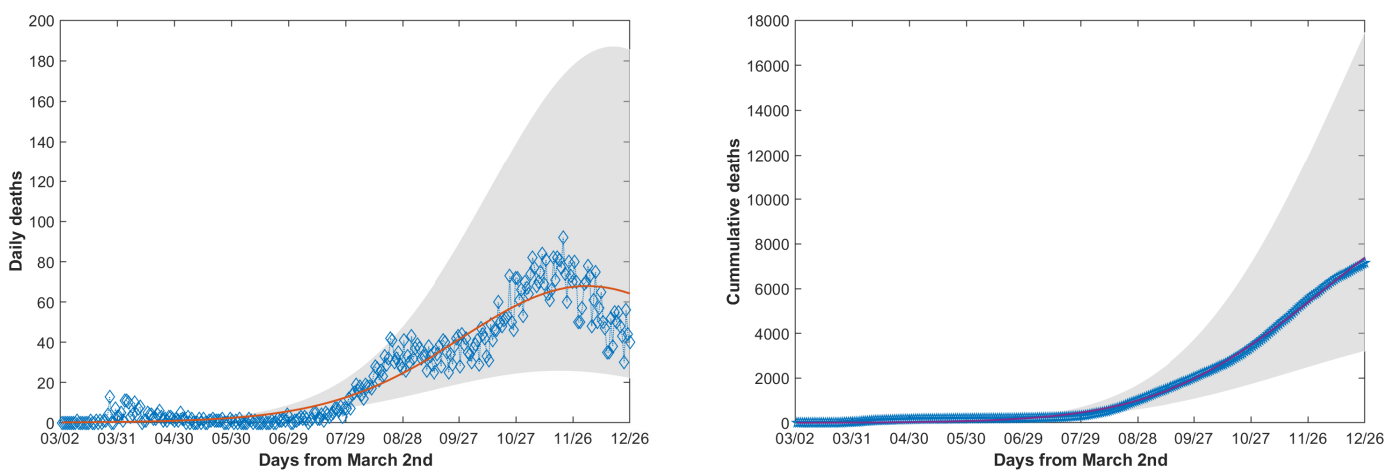

Figure 2.2: COVID-19 mortality data and fitting results in Morocco using model 2.1 in the absence of vaccination between March 2nd, 2020 and December 26th, 2020.

\subsection{Model formulation}

The population considered in this section is stratified into two age categories and eight disease status. Individuals are classified as unvaccinated susceptible children $\left(T_{u}\right)$, unvaccinated susceptible adults $\left(S_{u}\right)$, vaccinated susceptible adults $\left(S_{v}\right)$, asymptomatic infectious adults $(A)$, asymptomatic infectious children $(B)$, unreported symptomatic infectious $\left(I_{u}\right)$, hospitalized symptomatic infectious $(H)$, recovered individuals $(R)$ and COVID-deceased individuals $(D)$. We assume that infected children do not show symptoms and can still transmit the disease. COVID-19 disease dynamics can be described as follows: Susceptible children are born at rate $\pi_{T}$ and move to the susceptible adult class at rate $\alpha$. Unvaccinated susceptible individuals that are vaccinated at rate $p$ and acquire immunity from the vaccine at rate $\epsilon$ move to the vaccinated class $\left(S_{v}\right)$. It is assumed that vaccination does 
not necessarily induce lifelong immunity. Thus, vaccinated susceptible individuals are also assumed to acquire COVID-19 infection with a protective efficacy $\psi$, following effective contact with asymptomatic or unreported infected individuals. Furthermore, it is assumed that vaccinated class $\left(S_{v}\right)$ receives a booster dose as a second administration of the vaccine, at a rate $\phi$, to maintain successful immunization. Unvaccinated susceptible adults $\left(S_{u}\right)$ (resp. vaccinated susceptible adults $\left(S_{v}\right)$, susceptible children $(T)$ ) are infected through contact with infectious adults $\left(A+I_{u}\right)$ at a transmission rate $\beta_{a a}$ (resp. $\left.(1-\psi) \beta_{a a}, \beta_{c a}\right)$ or through contact with infectious children $(B)$ at a transmission rate $\beta_{a c}$ (resp. $(1-\psi) \beta_{a c}$, $\beta_{c c}$ ). Once infected, children and adults move, respectively, to the asymptomatic infectious class $(B)$ and the asymptomatic infectious class $(A)$. After an average period $1 / \delta$ days the asymptomatic infectious individuals $(A)$ become symptomatic and proceed either to the unreported symptomatic infectious $\left(I_{u}\right)$, at rate $\delta_{1}$, or to the hospitalized individual $(H)$ at rate $\delta_{2}$ with $\delta=\delta_{1}+\delta_{2}$. Once becoming symptomatic, individuals of class $I_{u}$ and $H$ either remain asymptomatic for $1 / \mu$ days on average before they are recovered or remain asymptomatic for $1 / d$ days on average before they are dead due to infection. Asymptomatic children can either be recovered without being hospitalized at rate $\delta$ or detected and hospitalized at rate $\sigma$. All individuals are naturally dead at rate $d_{N}$. The model will be given by the following equations

$$
\left\{\begin{aligned}
\frac{d T_{u}}{d t} & =\pi_{T}-\left(\beta_{a c} T_{u}(t)\left(A(t)+I_{u}(t)\right)+\beta_{c c} T_{u}(t) B(t)\right)-\left(d_{N}+\alpha\right) T_{u}(t), \\
\frac{d B}{d t} & =\beta_{a c} T_{u}(t)\left(A(t)+I_{u}(t)\right)+\beta_{c c} T_{u}(t) B(t)-\left(\sigma+\delta+d_{N}+\alpha\right) B(t), \\
\frac{d S_{u}}{d t} & =\alpha T_{u}(t)-\left(\beta_{a a} S_{u}(t)\left(A(t)+I_{u}(t)\right)+\beta_{c a} S_{u}(t) B(t)\right)-p_{S} \epsilon S_{u}(t)-d_{N} S_{u}(t), \\
\frac{d S_{v}}{d t} & =p_{S} \epsilon S_{u}(t)-(1-\psi)\left(\beta_{a a} S_{v}(t)\left(A(t)+I_{u}(t)\right)+\beta_{c a} S_{v}(t) B(t)\right)-d_{N} S_{v}(t)-\phi S_{v}(t), \\
\frac{d A}{d t} & =\alpha B(t)+\beta_{a a} S_{u}(t)\left(A(t)+I_{u}(t)\right)+\beta_{c a} S_{u}(t) B(t)-\left(\delta+d+d_{N}\right) A(t) \\
& +(1-\psi)\left(\beta_{a a} S_{v}(t)\left(A(t)+I_{u}(t)\right)+\beta_{c a} S_{v}(t) B(t)\right), \\
\frac{d I_{u}}{d t} & =\delta_{1} A(t)-\left(\mu+d+d_{N}\right) I_{u}(t), \\
\frac{d H}{d t} & =\delta_{2} A(t)+\sigma B(t)-\left(\mu+d+d_{N}\right) H, \\
\frac{d R}{d t} & =\delta B(t)+\mu\left(H+I_{u}\right)-d_{N} R+\phi S_{v}(t), \\
\frac{d D}{d t} & =d\left(A+I_{u}+H\right) .
\end{aligned}\right.
$$

\subsection{Parameter and Initial Data Estimation}

To estimate the model parameters we will use the data between March 2nd and March $20 t h, 2020$ during which there were no control measure. We will assume that $S_{v}=0, p_{S}=0$ and $\epsilon=0$. Note that the first infected child under 18 years was reported 22 days since the beginning of the epidemic. Furthermore, the maximum asymptomatic duration is assumed to 
be around 6 days. Consequently, it is meaningful to assume that there were no asymptomatic infected children (i.e. $B(0)=0$ ) under 18 years old at time $t=0$.

The cumulative reported infectious population is given, for $t \geq 0$, by $F(t)=\delta_{2} \int_{0}^{t} A(s) d s+$ 1. It is obvious that cumulative reported infectious population increases slowly and then accelerates rapidly with time. Hence, we will use exponential regression with $95 \%$ of confidence level to find an exponential function that best fits the data, from March 2nd to June 10th. Using SPSS software (Statistical Package for the Social Sciences) we found that the exponential model, given by $b e^{a t}$ where $a=0.263$ with confidence interval $C I(0.229-0.297)$ and $b=0.507$ with $C I(0.3444-0.7475)$ fits well the data with a correlation coefficient given by $R=0.97$. It follows from $F(t)=\delta_{2} \int_{0}^{t} A(s) d s+1=b e^{a t}$ that

$$
A(t)=\frac{b a}{\delta_{2}} e^{a t} .
$$

Table 1: Parameter definitions and values of model 2.1.

\begin{tabular}{|c|c|c|c|c|}
\hline Symbol & Definition & $\begin{array}{l}\text { Parameter } \\
\text { value }\end{array}$ & $\begin{array}{l}\text { Confidence } \\
\text { interval }\end{array}$ & Reference \\
\hline$S_{u}(0)$ & Initial susceptible population & 23428191 & & 20 \\
\hline$T_{u}(0)$ & Initial susceptible children & 12437000 & & 20 \\
\hline$S_{v}(0)$ & Initial vaccinated population & 0 & & See text \\
\hline$A(0)$ & Initial asymptomatic population & 0.9 & $0.48-1.357$ & 19 \\
\hline$I_{u}(0)\left(\times 10^{-2}\right.$ & $\begin{array}{l}\text { Initial unreported symptomatic } \\
\text { population }\end{array}$ & 6 & $2.9-8.3$ & 19 \\
\hline$H(0)$ & $\begin{array}{l}\text { Initial reported symptomatic } \\
\text { population }\end{array}$ & 1 & & See text \\
\hline$R(0)$ & Initial recovered population & 0 & & See text \\
\hline$D(0)$ & Initial COVID-deceased population & 0 & & See text \\
\hline$\beta_{a a}\left(\times 10^{-9}\right)$ & $\begin{array}{l}\text { Infection rate from infectious adults to } \\
\text { individuals }\end{array}$ & 8 & $6.82-10.77$ & Estimated \\
\hline$\beta_{c c}\left(\times 10^{-9}\right)$ & $\begin{array}{l}\text { Infection rate from infectious children } \\
\text { to individuals }\end{array}$ & 1.14 & $0.97-1.5$ & Estimated \\
\hline$\alpha\left(\times 10^{-4}\right)$ & $\begin{array}{l}\text { Leaving rate of children under } 18 \text { years } \\
\text { old }\end{array}$ & 1,52 & & Calculated \\
\hline $1 / \delta$ & Asymptomatic duration & 6 days & & 48 \\
\hline$\delta_{1}$ & Asymptomatic unreported rate & $\begin{array}{l}0.017 \text { per } \\
\text { day }\end{array}$ & & Assumed \\
\hline$\delta_{2}$ & Symptomatic reported rate & 0.15 per day & & Assumed \\
\hline $1 / \mu$ & Symptomatic duration & 14 days & & 58 \\
\hline$p_{S}$ & $\begin{array}{l}\text { Proportion of primary vaccination } \\
\text { under booster administration }\end{array}$ & $0-1$ & & Varied \\
\hline$d$ & Death rate from infection & 0.16 & & Estimated \\
\hline$\epsilon$ & Immunogenicity & $0-1$ & & Varied \\
\hline$\psi$ & Efficacy of the vaccine & $0-1$ & & Varied \\
\hline$\phi$ & Rate of second dose of vaccine & $1 / 21$ & & Calculated \\
\hline$\pi_{T}$ & Birth rate & 1572 & & 20 \\
\hline$d_{N}\left(\times 10^{-5}\right)$ & Natural death rate & 3.34 & & 20 \\
\hline
\end{tabular}


Since the initial susceptible population is not dramatically affected in the early phase of the epidemic, we will assume that $S_{u}(t) \approx S_{u}(0)$. Let $S_{0}:=S_{u}(0), A_{0}:=A(0)$ and $I_{0}:=I_{u}(0)$. From the fifth equation of system (2.1) and using (2.2) we obtain

$$
I_{u}(t)=I_{0} e^{a t},
$$

where

$$
I_{0}=\frac{b a}{\delta_{2}} \frac{a+\delta+d+d_{N}-\beta_{a a} S_{u}(0)}{\beta_{a a} S_{u}(0)} .
$$

Now, using formulas $(2.3)$ and the sixth equation of system (2.1), we obtain after simplification

$$
a I_{0}=\delta_{1} A_{0}-\left(\mu+d+d_{N}\right) I_{0}
$$

It follows that

$$
I_{0}=\frac{\delta_{1}}{a+\mu+d+d_{N}} A_{0} .
$$

Furthermore, $S_{v}(0)=0, T_{u}(0)=12437000$ and $S_{u}(0)=23428191$. We calculate the leaving rate of children under 18 years old to adults as $1 / \alpha=18 \times 365$ days, thus, $\alpha=1,52 \times 10^{-4}$. Since the Moroccan authorities decided to give the second dose of the vaccine after 21 days following the first dose then we assume that $\phi=1 / 21$. As mentioned in Section 1, we assume that $\beta_{a c}=\beta_{a a}$ and $\beta_{c a}=\beta_{c c}$. To estimate the transmission rates, $\beta_{a a}, \beta_{c c}$ and $d$, we use the nonlinear least squares solver "lsqcurvefit" in MATLAB R2019b software. The values of the estimated parameters are summarized in Table 1 .

\section{Results}

Since the three last components $H, R$ and $D$ do not appear in the six first equations of model (2.1) then we will focus our local stability study on the following system.

$$
\left\{\begin{aligned}
\frac{d T_{u}}{d t} & =\pi_{T}-\left(\beta_{a c} T_{u}(t)\left(A(t)+I_{u}(t)\right)+\beta_{c c} T_{u}(t) B(t)\right)-\left(d_{N}+\alpha\right) T_{u}(t), \\
\frac{d B}{d t} & =\beta_{a c} T_{u}(t)\left(A(t)+I_{u}(t)\right)+\beta_{c c} T_{u}(t) B(t)-\left(\sigma+\delta+d_{N}+\alpha\right) B(t), \\
\frac{d S_{u}}{d t} & =\alpha T_{u}(t)-\left(\beta_{a a} S_{u}(t)\left(A(t)+I_{u}(t)\right)+\beta_{c a} S_{u}(t) B(t)\right)-p_{S} \epsilon S_{u}(t)-d_{N} S_{u}(t), \\
\frac{d S_{v}}{d t} & =p_{S} \epsilon S_{u}(t)-(1-\psi)\left(\beta_{a a} S_{v}(t)\left(A(t)+I_{u}(t)\right)+\beta_{c a} S_{v}(t) B(t)\right)-d_{N} S_{v}(t)-\phi S_{v}(t), \\
\frac{d A}{d t} & =\alpha B(t)+\beta_{a a} S_{u}(t)\left(A(t)+I_{u}(t)\right)+\beta_{c a} S_{u}(t) B(t)-\left(\delta+d+d_{N}\right) A(t) \\
& +(1-\psi)\left(\beta_{a a} S_{v}(t)\left(A(t)+I_{u}(t)\right)+\beta_{c a} S_{v}(t) B(t)\right) \\
\frac{d I_{u}}{d t} & =\delta_{1} A(t)-\left(\mu+d+d_{N}\right) I_{u}(t),
\end{aligned}\right.
$$


medRxiv preprint doi: https://doi.org/10.1101/2021.03.14.21253555; this version posted March 17, 2021. The copyright holder for this preprint (which was not certified by peer review) is the author/funder, who has granted medRxiv a license to display the preprint in It is made available under a CC-BY-NC-ND 4.0 International license .

It is obvious that the model (3.1) has a unique disease free equilibrium (DFE) which is given by $\bar{E}=\left(\overline{T_{u}}, 0, \overline{S_{u}}, \overline{S_{v}}, 0,0\right)$, where

$$
\overline{T_{u}}=\frac{\pi_{T}}{d_{N}+\alpha}, \overline{S_{u}}=\frac{\alpha}{p_{S} \varepsilon+d_{N}} \overline{T_{u}} \text { and } \overline{S_{v}}=\frac{p_{S} \varepsilon}{d_{N}+\phi} \overline{S_{u}} .
$$

\subsection{Control reproduction number}

The control reproduction number, $R_{c}$, is an important value, used to determine whether a control policy, such as lockdown, lifting, behavioral practices, vaccination, etc, will be efficient to decrease the number of secondary infections to be less than one. In the absence of any control, this number is considered as the basic reproduction number, $R_{0}$, which is the average number of secondary infections produced when one infectious individual is introduced into a host susceptible population. This quantity determines whether a given disease may spread, or die out in a population. Applying the next generation matrix method formulated in [51], $R_{c}$ can be given by

$$
\begin{aligned}
\mathcal{R}_{c} & =\frac{\beta_{c c}}{\sigma+\delta+d_{N}+\alpha} \overline{T_{u}}+\frac{\beta_{a a}\left(\mu+d+d_{N}+\delta_{1}\right)\left(p_{S} \varepsilon+d_{N}\right)}{\left(\sigma+\delta+d_{N}+\alpha\right)\left(\delta+d+d_{N}\right)\left(\mu+d+d_{N}\right)} \overline{S_{u}} \\
& +\frac{\beta_{a a}\left(d_{N}+(1-\psi) p_{S} \varepsilon\right)\left(\mu+d+d_{N}+\delta_{1}\right)}{p_{S} \varepsilon\left(\delta+d+d_{N}\right)\left(\mu+d+d_{N}\right)} \overline{S_{v}} .
\end{aligned}
$$

The calculation of $R_{c}$ can be found in Appendix A

\subsection{Dynamics of the disease-free equilibrium}

The local behavior of the DFE of system (3.1) is given by the following theorem.

Theorem 1. The disease-free equilibrium is locally asymptotically stable for $\mathcal{R}_{c}<1$ and unstable for $\mathcal{R}_{c}>1$.

The proof of Theorem 1 can be found in Appendix B. The next lemma will be useful to prove the global stability of the DFE.

Lemma 2. The region

$$
\Omega=\left\{\left(T_{u}, B, S_{u}, S_{v}, A, I_{u}\right) \in \mathbb{R}_{+}^{6} / T_{u}+B+S_{u}+S_{v}+A+I_{u} \leq \frac{\pi_{T}}{d_{N}}\right\}
$$

is positively invariant and attracting with respect to system (3.1)).

The proof of Lemma 2 can be found in Appendix C.

Put

$$
\begin{aligned}
\Theta & =\frac{\beta_{c c} \pi_{T}}{\left(d_{N}+\phi\right)\left(\sigma+\delta+d_{N}+\alpha\right)}+\frac{\beta_{a a} \pi_{T}(2-\psi)\left(\mu+d+d_{N}+\delta_{1}\right)}{\left(d_{N}+\phi\right)\left(\mu+d+d_{N}\right)\left(\delta+d+d_{N}\right)} \\
& +\frac{\beta_{a a} \pi_{T}\left(\mu+d+d_{N}+\delta_{1}\right)}{\left(d_{N}+\phi\right)\left(\mu+d+d_{N}\right)\left(\delta+d+d_{N}\right)\left(\sigma+\delta+d_{N}+\alpha\right)}
\end{aligned}
$$

Now we are in the position to state and prove the global asymptotic stability of the DFE. 
Theorem 3. Assume that $\Theta<1$ and $\mathcal{R}_{c} \leq 1$, then the disease free equilibrium $\bar{E}$ of system (3.1)) is globally asymptotically stable in the region $\Omega$, i.e,

$$
\lim _{t \rightarrow \infty}\left(T_{u}, B, S_{u}, S_{v}, A, I_{u}\right)=\left(\overline{T_{u}}, 0, \overline{S_{u}}, \overline{S_{v}}, 0,0\right)
$$

The proof of Theorem 3 can be found in Appendix D.

Remark 4. Using parameter values in Table 3 and varying the vaccine efficacy values, $\psi$, in the range $[0,1]$, one can show that the parameter values of $\Theta$ vary in the range $[-0.9799,-0.9788]$. It follows that, in order to assure the global asymptotic stability, it suffices to assume that $\mathcal{R}_{c} \leq 1$.

\subsection{Herd immunity}

Herd immunity is defined as a level of population immunity at which the amount of virus able to spread in the entire population becomes very low so that the spread of the disease will be over. However, if the immunity level does not reach the herd immunity level, then a second wave of disease spread may appear. Thus, it is an interesting to look when herd immunity can be reached. Although natural herd immunity is considered as a way to reach herd immunity through natural recovery from COVID-19 infection, vaccination is considered as the best way to protect susceptible individuals and their community. Indeed, once plenty individuals are vaccinated and get immune from the disease, viruses cannot pass between individuals in the population and the whole community is less probably to contract the disease.

Note that the quantity $\varphi$, given in A.1, can be written as

$$
\varphi=\overline{S_{u}}+(1-\psi) \overline{S_{v}}
$$

Thus, $\mathcal{R}_{c}$ will be given by

$$
\begin{aligned}
\mathcal{R}_{c}=\frac{\overline{T_{u}}}{\sigma+\delta+d_{N}+\alpha}\left(\beta_{c c}+\right. & \left.\alpha \frac{\beta_{a a}\left(\mu+d+d_{N}+\delta_{1}\right)}{\left(\delta+d+d_{N}\right)\left(\mu+d+d_{N}\right)}\right) \\
& +\varphi \frac{\beta_{a a}\left(\mu+d+d_{N}+\delta_{1}\right)}{\left(\delta+d+d_{N}\right)\left(\mu+d+d_{N}\right)}
\end{aligned}
$$

So $\mathcal{R}_{c}=1$ is equivalent to

$$
\varphi=\frac{\left(\delta+d+d_{N}\right)\left(\mu+d+d_{N}\right)}{\beta_{a a}\left(\mu+d+d_{N}+\delta_{1}\right)}\left(1-\frac{\overline{T_{u}}}{\sigma+\delta+d_{N}+\alpha}\left(\beta_{c c}+\alpha \frac{\beta_{a a}\left(\mu+d+d_{N}+\delta_{1}\right)}{\left(\delta+d+d_{N}\right)\left(\mu+d+d_{N}\right)}\right)\right)
$$

On the other hand, we have $\varphi=N\left(1-\frac{\overline{T_{u}}}{N}-\psi \frac{\overline{S_{v}}}{N}\right)$, where $N$ is the total population size. Let $h_{v}=\frac{\overline{S_{v}}}{N}$ and $h_{T}=\frac{\overline{T_{u}}}{N}$, respectively, be the the proportions of susceptible individuals that have been vaccinated and susceptible children at the disease-free equilibrium. Set

$$
h_{v}^{c}=\frac{1}{\psi}\left(1-h_{T}-\left(\frac{\left(\delta+d+d_{N}\right)\left(\mu+d+d_{N}\right)}{N \beta_{a a}\left(\mu+d+d_{N}+\delta_{1}\right)}-\Lambda\right)\right)
$$


medRxiv preprint doi: https://doi.org/10.1101/2021.03.14.21253555; this version posted March 17, 2021. The copyright holder for this preprint (which was not certified by peer review) is the author/funder, who has granted medRxiv a license to display the preprint in It is made available under a CC-BY-NC-ND 4.0 International license .

where

$$
\Lambda=\frac{h_{T}}{\sigma+\delta+d_{N}+\alpha}\left(\frac{\beta_{c c}}{\beta_{a a}} \frac{\left(\delta+d+d_{N}\right)\left(\mu+d+d_{N}\right)}{\left(\mu+d+d_{N}+\delta_{1}\right)}+\alpha\right) .
$$

Note that, following Theorem 3 and Remark 4 , the disease free equilibrium $\bar{E}$ of system (3.1) is globally asymptotically stable if $\mathcal{R}_{c}<1$. Furthermore, $\mathcal{R}_{c}<1$ if and only if $h_{v}>h_{v}^{c}$ and, thus, for the herd immunity to be achieved, a proportion $h_{v}^{c}$, which is known as the herd immunity threshold, of the entire population should be vaccinated. Furthermore, if the vaccination is not successful at all $(\psi=0)$ then no matter the proportion of vaccinated adults, the eradication of the COVID-19 disease is implausible.

\section{Simulations and discussion}

The vaccination is among the most effective methods of preventing disease, disability, and death. A vaccine is defined as a suspension of live attenuated or inactivated pathogens, or fractions thereof, which is administered to induce immunity and prevent infectious disease or its sequelae [46]. Throughout 2020, a global effort have been undertaken to produce safe and effective vaccines against the newly emerged coronavirus, SARS-CoV-2. Actually, several of them received approval to initiate the national and multi-country mass vaccination campaigns. Morocco also will launch an emergency vaccination program for the adult population using vaccines produced by pharmaceutical firm Sinopharm and Astrazeneca. Over a period of 3 months, susceptible adult people who volunteer for the vaccination will receive two injections of vaccine spaced by 21 days apart [49]. Generally, the first dose induces a primary immune response by exposing the body for the first time to antigens. This immune response is often slow, limited and do not lead to protective immunity [45]. Therefore, a subsequent dose, also called a booster shot, is required to induce a secondary immune response in order to maintain an immunological memory which provides a long-time immunity. Indeed, the long-lived antibodies and memory cells have the ability to respond faster and more efficiently to the re-exposure to the same antigens [1]. Unfortunately, it is still too early to assess the duration of immunity provided by all anti-COVID-19 vaccines [3, 9]. Moreover, our understanding to the magnitude and duration of the immune response to natural infection with SARS-CoV-2 remains limited to date [12]. But it is well known that, for the common coronaviruses, the protective immunity is short-lasting and the reinfection often occurs 12 months after infection [8, 16]. For the SARS-CoV-2, several studies have shown that the immunity wanes over time and can be maintained only for few months after infection [54, 25, 44, 14]. Furthermore, the report of many cases of secondary infections with the COVID-19 in the same year also provides evidence that the acquired immunity is short-lived [16]. In case the protective immunity, conferred by the infection, is transient like for the coronavirus diseases, it will be necessary to plan periodic vaccination campaigns in coming years to prevent future outbreaks [40, 12].

In this study, we used a discrete age-structured mathematical model to assess the SARSCoV-2 vaccination program adopted by Morocco incorporating the efficacy and immunogenicity of the used vaccine and the vaccination rate of adult population. The data used for 
medRxiv preprint doi: https://doi.org/10.1101/2021.03.14.21253555; this version posted March 17, 2021. The copyright holder for this preprint (which was not certified by peer review) is the author/funder, who has granted medRxiv a license to display the preprint in

It is made available under a CC-BY-NC-ND 4.0 International license .

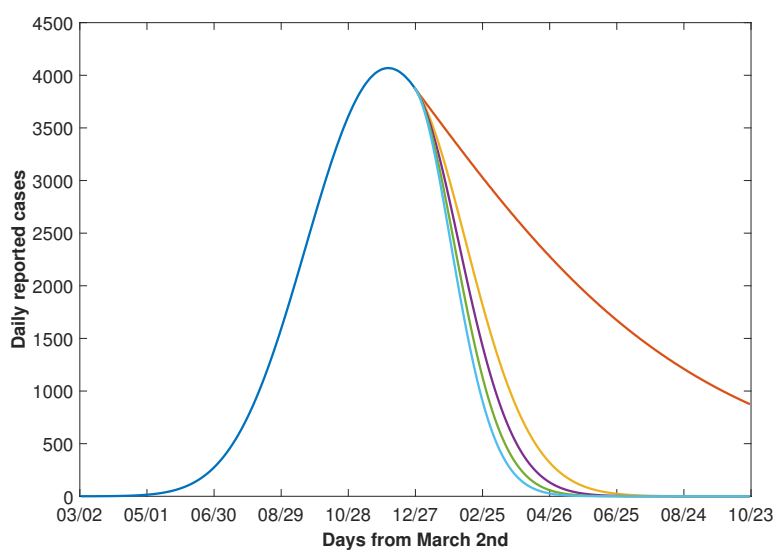

Figure 4.1: Daily reported cases over time. Daily reported cases are shown when vaccination is given with levels, from top to bottom, $0,0.5,0.6,0.7$ and $0.8 \%$ per day. Vaccine efficacy $(\psi)$ is assumed to be 90 and the immunogenicity $(\epsilon)$ is assumed to be $50 \%$.

simulations include implicitly the effect of the NPI (i.e. wearing masks; social distancing; cleaning and disinfecting measures...) applied between March 2nd, 2020 and December 26th, 2020 on COVID-19 disease spread. Based on our results, the COVID-19 is likely to persist past 2021 in the absence of a vaccine. Indeed, the number of daily reported cases and deaths tend to decline slowly over time, reaching, respectively, a number of 800 and 10 cases per day by the end of 2021 (See Fig. 4.1 and Fig. 4.2).

However, although it takes many months, vaccinating adults could help to eradicate the disease more quickly. The Moroccan people will have to wait until the second half of 2021 before definitively abandoning the NPI. Several studies have shown that when the NPI are maintained during the vaccination program, the COVID-19 elimination is greatly improved in the country such as the US and South Africa [24, 4, 36].

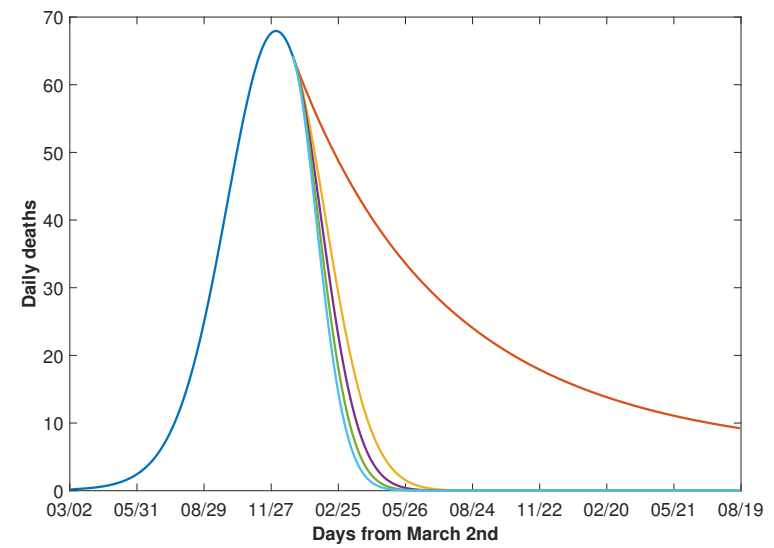

Figure 4.2: Daily death cases over time. Daily mortality cases are shown when vaccination is given with levels, from top to bottom, 0, 0.5, 0.6, 0.7 and $0.8 \%$ per day. Vaccine efficacy $(\psi)$ is assumed to be 90 and the immunogenicity $(\epsilon)$ is assumed to be $50 \%$.

They also found that, in the absence of NPI, the vaccines with at least $70 \%$ efficacy are able to contain COVID-19 outbreak but higher vaccination coverage is needed. In the case of 


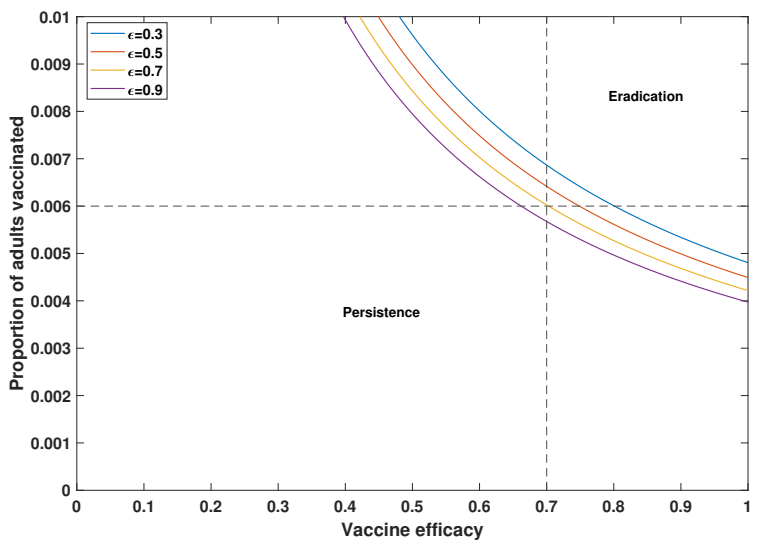

Figure 4.3: Vaccination thresholds for eradication depending on vaccine efficacy for the four levels of immunogenicity, from top to bottom, 30\%, 50\%, $70 \%$ and $90 \%$ at the time of vaccination. The vertical line corresponds to $\psi=0.7$ while the horizontal line corresponds to $p_{S}=0.006$.

Morocco, the efficacy and immunogenicity of the vaccine needed to eradicate the COVID-19 depend on the proportion of adults vaccinated daily. Indeed, if the Moroccan government plans to immunize the adult population at a rate of $0.6 \%$ per day, then the used vaccine must have an efficacy rate of at least $67 \%$ and generate a strong immunogenicity $(\epsilon=0.9)$ in vaccinated individuals to achieve the disease eradication (Fig. 4.3). The use of UK's OxfordAstrazeneca or China's Sinopharm vaccine that have, respectively, a efficacy rate of $70 \%$ or $79 \%$ in vaccinating the adult population may be powerful tool in the COVID-19 eradication while still maintaining the NPI [28]. However, although difficult to enact, if the Moroccan health care is able to increase the vaccination rate to $1 \%$ per day, then vaccine has to have at least $40 \%$ of efficacy to eradicate the disease (Fig. 4.3). So the success of the vaccination program depends not only on the efficacy rate of vaccine and the degree of the generated immune response but depends also on the logistical resources deployed to ensure vaccination of large numbers of individuals within a short space of time. Paltiel and its collaborators [41] also showed that the advantages of a vaccine can decline significantly in the event of manufacturing or deployment delays, significant vaccine hesitancy, or greater epidemic severity. Many pharmaceutical companies have taken up the challenge of supplying the world with the first anti-COVID-19 vaccines at the end of 2020. However, they are now facing a new challenge to produce a sufficient quantity of COVID-19 vaccines of high quality to cover the demand of all emerging and non-emerging countries affected by this pandemic. According to scientific news published by Cohen and Kupferschmidt in [12], it will be necessary to wait for the year 2022 to assure enough vaccines available to vaccinate people wishing to be vaccinated. Fortunately, reaching the so-called "herd immunity threshold" could have an indirect effect on the protection of the unvaccinated susceptible people against the infection. The notion of herd immunity threshold is defined as the proportion of immunized individuals, through natural infection or through vaccination, in a population who cannot get infected anymore [40]. Generally, although herd immunity threshold varies with each disease, a large proportion of individuals must be immunized to achieve the herd immunity. For the 
medRxiv preprint doi: https://doi.org/10.1101/2021.03.14.21253555; this version posted March 17, 2021. The copyright holder for this preprint (which was not certified by peer review) is the author/funder, who has granted medRxiv a license to display the preprint in

It is made available under a CC-BY-NC-ND 4.0 International license .

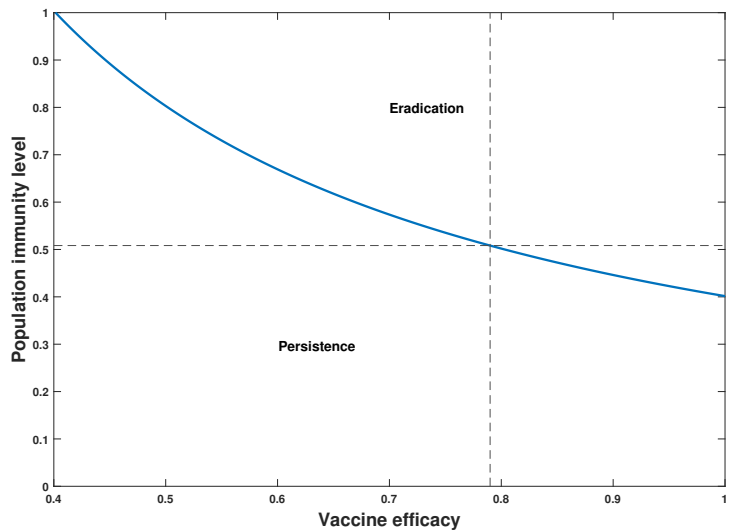

Figure 4.4: Population immunity threshold for eradication depending on vaccine efficacy at the time of vaccination. The vertical line corresponds to $\psi=0.79$ while the horizontal line corresponds to $h_{v}=0.508$.

COVID-19, the herd immunity threshold is still unknown and will probably vary depending on the community and the vaccination strategy adopted by the country in question among others 62. However, several studies using mathematical modeling were able to estimate this threshold [24, 4, 36]. For example, by assuming a vaccine with $80 \%$ of efficacy, Iboi and collaborators [24] found that at least $82 \%$ of susceptible population in US must be immunized against the SARS-CoV-2 to achieve the herd immunity threshold. Moreover, they also found that this percentage could drop to $72 \%$ (resp. 46\%) with a regular wearing of masks by the half of the population (resp. the entire population). In our case, the herd immunity is achieved when about half of Moroccan adult population is immunized against the COVID-19 with a vaccine efficacy rate of $79 \%$ like the one by Sinopharm vaccine (See Figure 4.4). However, with an efficacy rate of $70 \%$ such as the case of Oxford-Astrazeneca vaccine, less than $60 \%$ of adult population must be immunized against the disease to achieve the herd immunity.

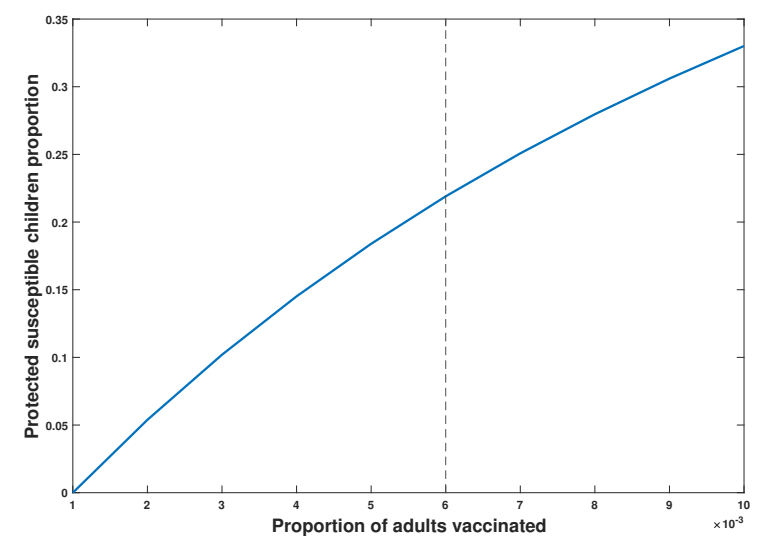

Figure 4.5: Proportions of protected susceptible children with different levels of vaccination. Proportions of protected susceptible children increases as vaccine uptake increases in the total adult population. Vaccine efficacy $(\psi)$ is assumed to be 80 and the immunogenicity $(\epsilon)$ is assumed to be $50 \%$. The vertical line corresponds to $p_{S}=0.006$. (Protected are $22 \%$ of susceptible children) 
These proportions should probably be higher than estimated since our model also takes into account the combined effects of the NPIs and vaccine.

Finally, note that COVID-19 vaccines obviously provide direct protection to adults but can also produce indirect protection and block the course of infection to children. The Fig. 4.5 shows that, if vaccine efficacy is about $80 \%$ and the immunogenicity is about $50 \%$, then protected susceptible children increases as vaccine uptake increases in the total adult population. In particular, $0.6 \%$ of vaccinated adults could save about $22 \%$ of children from infection.

\section{Conclusion}

While waiting for the first doses of vaccines since the end of December 2020, Morocco is preparing for the vaccination campaign of the adult population to eradicate the COVID-19 epidemic. Our findings show that, with a vaccination rate of $0.6 \%$ per day, the vaccine must both have an efficacy rate of at least $67 \%$ and must provide a high degree of immunity to people vaccinated. In addition, it is also necessary to continue to take protective measures during the vaccination period to achieve the herd immunity threshold more quickly. Our results found that the herd immunity can be obtained by immunizing less than $60 \%$ of the adult population against the COVID-19 with a vaccine with $70 \%$ or more of efficacy. Finally, this vaccination program can also protect $22 \%$ of susceptible children from infection. However, in order not to devalue the efficacy of the vaccine used and before starting vaccination campaign, the Moroccan government must ensure the availability of all doses of vaccine needed to cover the entire target population, encourage the concerned people to be vaccinated, and carry out all vaccinations in the shortest time in accordance with the human, logistical and financial resources of country.

\section{Acknowledgments}

The authors thank the anonymous referees, whose careful reading, insights, valuable comments, and suggestions significantly enabled us to improve the quality of the paper.

\section{Appendix A}

Following the notation in [51], the associated next generation matrices, $F$ and $V$, for the new infection terms and the transition terms, are given, respectively, by

$$
F=\left(\begin{array}{ccc}
\frac{\beta_{c c} \pi_{T}}{d_{N}+\alpha} & \frac{\beta_{a c} \pi_{T}}{d_{N}+\alpha} & \frac{\beta_{a c} \pi_{T}}{d_{N}+\alpha} \\
\beta_{c a} \varphi & \beta_{a a} \varphi & \beta_{a a} \varphi \\
0 & 0 & 0
\end{array}\right)
$$

and

$$
V=\left(\begin{array}{ccc}
\sigma+\delta+d_{N}+\alpha & 0 & 0 \\
-\alpha & \delta+d+d_{N} & 0 \\
0 & -\delta_{1} & \mu+d+d_{N}
\end{array}\right)
$$


where

$$
\varphi=\frac{\alpha \pi_{T}\left(d_{N}+\phi+(1-\psi) p_{S} \varepsilon\right)}{\left(p_{S} \varepsilon+d_{N}\right)\left(d_{N}+\alpha\right)\left(d_{N}+\phi\right)} .
$$

We have $\operatorname{det}(V)=\left(\sigma+\delta+d_{N}+\alpha\right)\left(\delta+d+d_{N}\right)\left(\mu+d+d_{N}\right)$. Then, the inverse of $V$ is given by

$$
V^{-1}=\left(\begin{array}{ccc}
\frac{1}{\sigma+\delta+d_{N}+\alpha} & 0 & 0 \\
\frac{\alpha}{\left(\sigma+\delta+d_{N}+\alpha\right)\left(\delta+d+d_{N}\right)} & \frac{1}{\delta+d_{1}+d_{N}} & 0 \\
\frac{\alpha \delta_{1}}{\left(\sigma+\delta+d_{N}+\alpha\right)\left(\delta+d+d_{N}\right)\left(\mu+d+d_{N}\right)} & \frac{\delta_{1}}{\left(\delta+d+d_{N}\right)\left(\mu+d+d_{N}\right)} & \frac{1}{\mu+d+d_{N}}
\end{array}\right) .
$$

Thus, the next generation matrix for system $([3.1)$ will be given by

$$
F V^{-1}=\left(\begin{array}{ccc}
\alpha_{1} & \alpha_{2} & \alpha_{3} \\
\alpha_{4} & \alpha_{5} & \alpha_{6} \\
0 & 0 & 0
\end{array}\right)
$$

where

$$
\left\{\begin{aligned}
\alpha_{1} & =\frac{\beta_{c c} \pi_{T}}{\sigma+\delta+d_{N}+\alpha}+\frac{\alpha \beta_{a c} \pi_{T}\left(\mu+d+d_{N}+\delta_{1}\right)}{\left(\sigma+\delta+d_{N}+\alpha\right)\left(\delta+d+d_{N}\right)\left(\mu+d+d_{N}\right)} \\
\alpha_{2} & =\frac{\beta_{a c} \pi_{T}\left(\mu+d+d_{N}+\delta_{1}\right)}{\left(\delta+d+d_{N}\right)\left(\mu+d+d_{N}\right)} \\
\alpha_{3} & =\frac{\beta_{a c} \pi_{T}}{\mu+d+d_{N}}, \\
\alpha_{4} & =\frac{\alpha \beta_{c a} \pi_{T}\left(d_{N}+(1-\psi) p_{S} \varepsilon\right)}{\left(p_{S} \varepsilon+d_{N}\right)\left(\sigma+\delta+d_{N}+\alpha\right)\left(d_{N}+\phi\right)} \\
& +\frac{\alpha \beta_{c a} \pi_{T}\left(d_{N}+(1-\psi) p_{S} \varepsilon\right)\left(\mu+d+d_{N}+\delta_{1}\right)}{\left(\sigma+\delta+d_{N}+\alpha\right)\left(\delta+d+d_{N}\right)\left(\mu+d+d_{N}\right)\left(p_{S} \varepsilon+d_{N}\right)\left(d_{N}+\phi\right)} \\
\alpha_{5} & =\frac{\alpha \beta_{a a} \pi_{T}\left(d_{N}+(1-\psi) p_{S} \varepsilon\right)\left(\mu+d+d_{N}+\delta_{1}\right)}{\left(p_{S} \varepsilon+d_{N}\right)\left(\delta+d+d_{N}\right)\left(\mu+d+d_{N}\right)\left(d_{N}+\phi\right)} \\
\alpha_{6} & =\frac{\alpha \beta_{a a} \delta_{1} \pi_{T}\left(d_{N}+(1-\psi) p_{S} \varepsilon\right)}{\left(p_{S} \varepsilon+d_{N}\right)\left(\mu+d+d_{N}\right)\left(d_{N}+\phi\right)}
\end{aligned}\right.
$$

Therefore the associated characteristic equation is given by

$$
\triangle(\lambda)=\lambda^{2}-\lambda\left(Q_{1}+Q_{2}\right)
$$

where

$$
Q_{1}=\frac{\beta_{c c} \pi_{T}}{\left(d_{N}+\alpha\right)\left(\sigma+\delta+d_{N}+\alpha\right)}+\frac{\alpha \beta_{a a} \pi_{T}\left(\mu+d+d_{N}+\delta_{1}\right)}{\left(\sigma+\delta+d_{N}+\alpha\right)\left(\delta+d+d_{N}\right)\left(d_{N}+\alpha\right)\left(\mu+d+d_{N}\right)}
$$

and

$$
Q_{2}=\frac{\alpha \beta_{a a} \pi_{T}\left(d_{N}+(1-\psi) p_{S} \varepsilon\right)\left(\mu+d+d_{N}+\delta_{1}\right)}{\left(d_{N}+\alpha\right)\left(p_{S} \varepsilon+d_{N}\right)\left(\delta+d+d_{N}\right)\left(\mu+d+d_{N}\right)\left(d_{N}+\phi\right)} .
$$


medRxiv preprint doi: https://doi.org/10.1101/2021.03.14.21253555; this version posted March 17, 2021. The copyright holder for this preprint (which was not certified by peer review) is the author/funder, who has granted medRxiv a license to display the preprint in It is made available under a CC-BY-NC-ND 4.0 International license .

Therefore, by definition of $\mathcal{R}_{c}$, we obtain

$$
\mathcal{R}_{c}=\max \left\{0, Q_{1}+Q_{2}\right\}
$$

Consequently, the control reproduction number is given by formula 3.2 .

\section{Appendix B}

The local stability of $\bar{E}$ is governed by the eigenvalues of the Jacobian matrix, of system $(3.1)$,

$$
J(\bar{E})=\left(\begin{array}{cccccc}
a_{1,1} & a_{1,2} & 0 & 0 & a_{1,5} & a_{1,6} \\
0 & a_{2,2} & 0 & 0 & a_{2,5} & a_{2,6} \\
a_{3,1} & a_{3,2} & a_{3,3} & 0 & a_{3,5} & a_{3,6} \\
0 & a_{4,2} & a_{4,3} & a_{4,4} & a_{4,5} & a_{4,6} \\
0 & a_{5,2} & 0 & 0 & a_{5,5} & a_{5,6} \\
0 & 0 & 0 & 0 & a_{6,5} & a_{6,6}
\end{array}\right)
$$

where

$$
\left\{\begin{array}{lll}
a_{1,1}=-\left(d_{N}+\alpha\right), & a_{1,2}=\frac{-\beta_{c c} \pi_{T}}{d_{N}+\alpha}, \\
a_{1,5}=\frac{-\beta_{a c} \pi_{T}}{d_{N}+\alpha}, & a_{1,6}=\frac{-\beta_{a c} \pi_{T}}{d_{N}+\alpha}, \\
a_{2,2}=\frac{\beta_{c c} \pi_{T}}{d_{N}+\alpha}-\left(\sigma+\delta+d_{N}+\alpha\right), & a_{2,5}=\frac{\beta_{a c} \pi_{T}}{d_{N}+\alpha} \\
a_{2,6}=\frac{\beta_{a c} \pi_{T}}{\left(d_{N}+\alpha\right)}, & a_{3,1}=\alpha, \\
a_{3,2}=-\frac{\beta_{c a} \alpha \pi_{T}}{\left(d_{N}+\alpha\right)\left(p_{S} \varepsilon+d_{N}\right)}, & a_{3,3}=-\left(p_{S} \varepsilon+d_{N}\right), \\
a_{3,5}=-\frac{\beta_{a a} \alpha \pi_{T}}{\left(d_{N}+\alpha\right)\left(p_{S} \varepsilon+d_{N}\right)}, & a_{3,6}=-\frac{\beta_{a a} \alpha \pi_{T}}{\left(d_{N}+\alpha\right)\left(p_{S} \varepsilon+d_{N}\right)} \\
a_{4,2}=-\frac{(1-\psi) \beta_{c a} \alpha \pi_{T} p_{S} \varepsilon}{\left(d_{N}+\alpha\right)\left(p_{S} \varepsilon+d_{N}\right)\left(d_{N}+\phi\right)}, & a_{4,3}=p_{S} \varepsilon, \\
a_{4,4}=-\left(d_{N}+\phi\right), & a_{4,5}=-\frac{(1-\psi) \beta_{a a} \alpha \pi_{T} p_{S} \varepsilon}{\left(d_{N}+\alpha\right)\left(p_{S} \varepsilon+d_{N}\right)\left(d_{N}+\phi\right)}
\end{array}\right.
$$

and

$$
\left\{\begin{array}{lc}
a_{4,6}=-\frac{(1-\psi) \beta_{a a} \alpha \pi_{T} p_{S} \varepsilon}{\left(d_{N}+\alpha\right)\left(p_{S} \varepsilon+d_{N}\right)\left(d_{N}+\phi\right)}, & a_{5,2}=\alpha+\frac{\beta_{c a} \alpha \pi_{T}}{\left(d_{N}+\alpha\right)\left(p_{S} \varepsilon+d_{N}\right)} \\
a_{5,5}=\frac{\beta_{a a} \alpha \pi_{T}}{\left(d_{N}+\alpha\right)\left(p_{S} \varepsilon+d_{N}\right)} & +\frac{(1-\psi) \beta_{c a} \alpha \pi_{T} p_{S} \varepsilon}{\left(d_{N}+\alpha\right)\left(p_{S} \varepsilon+d_{N}\right)\left(d_{N}+\phi\right)}, \\
+\frac{(1-\psi) \beta_{a a} \alpha \pi_{T} p_{S} \varepsilon}{\left(d_{N}+\alpha\right)\left(p_{S} \varepsilon+d_{N}\right)\left(d_{N}+\phi\right)}-\left(\delta+d+d_{N}\right), & +\frac{a_{5,6}=\frac{(1-\psi) \beta_{a a} \alpha \pi_{T} p_{S} \varepsilon}{\left(d_{N}+\alpha\right)\left(p_{S} \varepsilon+d_{N}\right)}}{\left(d_{N}+\alpha\right)\left(p_{S} \varepsilon+d_{N}\right)\left(d_{N}+\phi\right)} \\
a_{6,5}=\delta_{1}, & a_{6,6}=-\left(\mu+d+d_{N}\right) .
\end{array}\right.
$$

Therefore the associated characteristic equation is

$$
P(\lambda)=\left(d_{N}+\alpha+\lambda\right)\left(d_{N}+\phi+\lambda\right)\left(p_{S} \varepsilon+d_{N}+\lambda\right)\left(\lambda^{3}+\alpha_{1} \lambda^{2}+\alpha_{2} \lambda+\alpha_{3}\right),
$$


where

$$
\begin{gathered}
\alpha_{1}=\mu+\alpha+2 d+3 d_{N}+\sigma+2 \delta-\beta_{c c} \frac{\pi_{T}}{\left(d_{N}+\alpha\right)}-\beta_{a a} \frac{\alpha \pi_{T}\left(d_{N}+(1-\psi) p_{S} \varepsilon\right)}{\left(d_{N}+\alpha\right)\left(p_{S} \varepsilon+d_{N}\right)\left(d_{N}+\phi\right)}, \\
\alpha_{2}=\left(\mu+d+d_{N}\right)\left(\sigma+d+2 d_{N}+2 \delta+\alpha-\beta_{c c} \frac{\pi_{T}}{\left(d_{N}+\alpha\right)}-\beta_{a a} \frac{\alpha \pi_{T}\left(d_{N}+(1-\psi) p_{S} \varepsilon\right)}{\left(d_{N}+\alpha\right)\left(p_{S} \varepsilon+d_{N}\right)\left(d_{N}+\phi\right)}\right) \\
+\left(\sigma+\delta+d_{N}+\alpha\right)\left(\delta+d+d_{N}\right)-\beta_{c c}\left(\delta+d+d_{N}\right) \frac{\pi_{T}}{\left(d_{N}+\alpha\right)}-\alpha \beta_{a a} \frac{\pi_{T}}{\left(d_{N}+\alpha\right)} \\
-\beta_{a a}\left(\sigma+\delta+d_{N}+\alpha+\delta_{1}\right) \frac{\alpha \pi_{T}\left(d_{N}+(1-\psi) p_{S} \varepsilon\right)}{\left(d_{N}+\alpha\right)\left(p_{S} \varepsilon+d_{N}\right)\left(d_{N}+\phi\right)}
\end{gathered}
$$

and

$$
\begin{aligned}
\alpha_{3} & =\left(\mu+d+d_{N}\right)\left[\left(\sigma+\delta+d_{N}+\alpha\right)\left(\delta+d+d_{N}\right)-\beta_{c c}\left(\delta+d+d_{N}\right) \frac{\pi_{T}}{d_{N}+\alpha}-\alpha \beta_{a a} \frac{\pi_{T}}{d_{N}+\alpha}\right. \\
& -\beta_{a a}\left(\sigma+\delta+d_{N}+\alpha\right) \frac{\alpha \pi_{T}\left(d_{N}+(1-\psi) p_{S} \varepsilon\right)}{\left(d_{N}+\alpha\right)\left(p_{S} \varepsilon+d_{N}\right)\left(d_{N}+\phi\right)}-\delta_{1} \alpha \beta_{a a} \frac{\pi_{T}}{d_{N}+\alpha} \\
& -\delta_{1} \beta_{a a}\left(\sigma+\delta+d_{N}+\alpha\right) \frac{\alpha \pi_{T}\left(d_{N}+(1-\psi) p_{S} \varepsilon\right)}{\left(d_{N}+\alpha\right)\left(p_{S} \varepsilon+d_{N}\right)\left(d_{N}+\phi\right)} .
\end{aligned}
$$

Then $-\left(d_{N}+\phi\right),-\left(p_{S} \varepsilon+d_{N}\right),-\left(d_{N}+\alpha\right)$ are roots of the characteristic equation (B.1) and, consequently, a necessary and sufficient condition for the other roots ta have negative real parts is given by the following lineard-chipart [32] criteria

$$
\left\{\begin{array}{l}
\alpha_{1}, \alpha_{3}>0 \\
\alpha_{1} \alpha_{2}-\alpha_{3}>0
\end{array}\right.
$$

On can see that

$$
\alpha_{3}=\left(\sigma+\delta+d_{N}+\alpha\right)\left(\delta+d+d_{N}\right)\left(\mu+d+d_{N}\right)\left(1-\mathcal{R}_{c}\right) .
$$

Moreover, if $\mathcal{R}_{c}<1$, then

$$
\left\{\begin{array}{l}
\frac{\beta_{c c} \pi_{T}}{d_{N}+\alpha}<\sigma+\delta+d_{N}+\alpha \\
\frac{\alpha \beta_{a a} \pi_{T}\left(d_{N}+(1-\psi) p_{S} \varepsilon\right)}{\left(d_{N}+\alpha\right)\left(p_{S} \varepsilon+d_{N}\right)\left(d_{N}+\phi\right)}<\frac{\left(\delta+d+d_{N}\right)\left(\mu+d+d_{N}\right)}{\mu+d+d_{N}+\delta_{1}} .
\end{array}\right.
$$

It follows that

$$
\begin{aligned}
\alpha_{1} & =\mu+\alpha+2 d+3 d_{N}+\sigma+2 \delta-\beta_{c c} \frac{\pi_{T}}{\left(d_{N}+\alpha\right)}-\beta_{a a} \frac{\alpha \pi_{T}\left(d_{N}+(1-\psi) p_{S} \varepsilon\right)}{\left(d_{N}+\alpha\right)\left(p_{S} \varepsilon+d_{N}\right)} \\
& >\mu+\alpha+2 d+3 d_{N}+\sigma+2 \delta-\left(\sigma+\delta+d_{N}+\alpha\right)-\left(\delta+d+d_{N}\right) \\
& =\mu+d+d_{N} .
\end{aligned}
$$


Thus, if $\mathcal{R}_{c}<1$ then $\alpha_{1}$ and $\alpha_{3}$ are positive. Now let's prove that $\alpha_{1} \alpha_{2}-\alpha_{3}>0$. After few simplification we can get

$$
\begin{aligned}
\left(\mu+d+d_{N}\right) \alpha_{2}-\alpha_{3} & =-\frac{\left(\mu+d+d_{N}\right) \delta_{1} \beta_{a a} \alpha \pi_{T}\left(d_{N}+(1-\psi) p_{S} \varepsilon\right)}{\left(d_{N}+\alpha\right)\left(p_{S} \varepsilon+d_{N}\right)\left(\left(d_{N}+\phi\right)\right)}+\frac{\left(\mu+d+d_{N}+\delta_{1}\right) \beta_{a a} \alpha \pi_{T}}{d_{N}+\alpha} \\
& +\frac{\delta_{1} \beta_{a a}\left(\sigma+\delta+d_{N}+\alpha\right) \alpha \pi_{T}\left(d_{N}+(1-\psi) p_{S} \varepsilon\right)}{\left(d_{N}+\alpha\right)\left(p_{S} \varepsilon+d_{N}\right) d_{N}}
\end{aligned}
$$

and, consequently,

$\left(\mu+d+d_{N}\right) \alpha_{2}-\alpha_{3}>\left(\delta+d+d_{N}\right)\left(\left(\mu+d+d_{N}\right)\left(\sigma+\delta_{2}+d_{N}+\alpha\right)+\delta_{1}\left(\sigma+\delta+d_{N}+\alpha\right)\right)>0$.

Furthermore, from $(\underline{\mathrm{B} .2})$ ), we have $\alpha_{1}>\mu+d+d_{N}$. Then, $\alpha_{1} \alpha_{2}>\left(\mu+d+d_{N}\right) \alpha_{2}>\alpha_{3}$. Finally, we have $\alpha_{1} \alpha_{2}-\alpha_{3}>0$. Hence, $\bar{E}$ is locally asymptotically stable for $\mathcal{R}_{c}<1$.

Assume now that $\mathcal{R}_{c}>1$. Since

$$
P(0)=\left(d_{N}+\alpha\right)\left(d_{N}+\phi\right)\left(p_{S} \varepsilon+d_{N}\right)\left(\sigma+\delta+d_{N}+\alpha\right)\left(\delta+d+d_{N}\right)\left(\mu+d+d_{N}\right)\left(1-\mathcal{R}_{c}\right),
$$

then $P(0)<0$. Moreover, when $\lambda \in \mathbb{R}$ then $\lim _{\lambda \rightarrow+\infty} P(\lambda)=+\infty$, Then, there exists $\lambda_{0}>0$ such that $P\left(\lambda_{0}\right)=0$ and the disease-free equilibrium becomes unstable. This completes the proof.

\section{Appendix C}

For the invariance property it suffices to show that the vector field, on the boundary, does not point to the exterior. On one hand, on the boundary of $\Omega$, we have

$$
M(t):=T_{u}(t)+B(t)+S_{u}(t)+S_{v}(t)+A(t)+I_{u}(t)=\frac{\pi_{T}}{d_{N}} .
$$

Then

$$
\frac{d M}{d t}=\pi_{T}-d_{N} M-(\sigma+\delta) B(t)-\phi S_{v}(t)-\left(\delta_{2}+d\right) A(t)-(\mu+d) I_{u}(t)
$$

and, consequently, $\frac{d M}{d t} \leq 0$. Therefore, solutions starting from $\Omega$, will remain there for $t \geq 0$. On the other hand, we have $\lim _{t \rightarrow \infty} \sup M(t) \leq \frac{\pi_{T}}{d_{N}}$. Hence, $\Omega$ is attracting, that is, all solutions of ([3.1) ) eventually enters $\Omega$. This completes the proof.

\section{Appendix D}

To prove the above result, we use the following Lyapunov function

$$
W=B+\frac{d_{N}\left(\sigma+\delta+d_{N}+\alpha\right)-\beta_{c c} \pi_{T}}{d_{N} \alpha+\beta_{c c} \pi_{T}(2-\psi)} A+\frac{\beta_{a a}\left(\left(\sigma+\delta+d_{N}+\alpha\right) \pi_{T}(2-\psi)+\alpha \pi_{T}\right)}{\left(\mu+d+d_{N}\right)\left(d_{N} \alpha+\beta_{c c} \pi_{T}(2-\psi)\right)} I_{u} .
$$


The orbital derivative of $W$ is given by

$$
\begin{aligned}
\frac{d W}{d t} & =\left[T_{u}\left(\beta_{a c}\left(A+I_{u}\right)+\beta_{c c} B\right)-\left(\sigma+\delta+d_{N}+\alpha\right) B\right] \\
& +\frac{d_{N}\left(\sigma+\delta+d_{N}+\alpha\right)-\beta_{c c} \pi_{T}}{\left(d_{N} \alpha+\beta_{c c} \pi_{T}(2-\psi)\right)}\left[\alpha B+S_{u}\left(\beta_{a a}\left(A+I_{u}\right)+\beta_{c a} B\right)\right. \\
& \left.+(1-\psi) S_{v}\left(\beta_{a a}\left(A+I_{u}\right)+\beta_{c a} B\right)-\left(\delta+d+d_{N}\right) A\right] \\
& +\frac{\beta_{a a}\left(\left(\sigma+\delta+d_{N}+\alpha\right) \pi_{T}(2-\psi)+\alpha \pi_{T}\right)}{\left(\mu+d+d_{N}\right)\left(d_{N} \alpha+\beta_{c c} \pi_{T}(2-\psi)\right)}\left[\delta_{1} A-\left(\mu+d+d_{N}\right) I_{u}\right] .
\end{aligned}
$$

Since $T_{u} \leq \frac{\pi_{T}}{d_{N}}, S_{u} \leq \frac{\pi_{T}}{d_{N}}$ and $S_{v} \leq \frac{\pi_{T}}{d_{N}}$, we obtain

$$
\begin{aligned}
\frac{d W}{d t} & \leq\left[\frac{\pi_{T}}{d_{N}}\left(\beta_{a c}\left(A+I_{u}\right)+\beta_{c c} B\right)-\left(\sigma+\delta+d_{N}+\alpha\right) B\right] \\
& +\frac{d_{N}\left(\sigma+\delta+d_{N}+\alpha\right)-\beta_{c c} \pi_{T}}{\left(d_{N} \alpha+\beta_{c c} \pi_{T}(2-\psi)\right)}\left[\alpha B+\frac{\pi_{T}}{d_{N}}\left(\beta_{a a}\left(A+I_{u}\right)+\beta_{c a} B\right)\right. \\
& \left.+(1-\psi) \frac{\pi_{T}}{d_{N}}\left(\beta_{a a}\left(A+I_{u}\right)+\beta_{c a} B\right)-\left(\delta+d+d_{N}\right) A\right] \\
& +\frac{\beta_{a a}\left(\left(\sigma+\delta+d_{N}+\alpha\right) \pi_{T}(2-\psi)+\alpha \pi_{T}\right)}{\left(\mu+d+d_{N}\right)\left(d_{N} \alpha+\beta_{c c} \pi_{T}(2-\psi)\right)}\left[\delta_{1} A-\left(\mu+d+d_{N}\right) I_{u}\right] .
\end{aligned}
$$

Thus,

$$
\begin{aligned}
\frac{d W}{d t} \leq & -\left[\sigma+\delta+d_{N}+\alpha-\alpha \frac{d_{N}\left(\sigma+\delta+d_{N}+\alpha\right)-\beta_{c c} \pi_{T}}{\left(d_{N} \alpha+\beta_{c c} \pi_{T}(2-\psi)\right)}\right. \\
& \left.-\beta_{c c} \frac{\pi_{T}}{d_{N}}\left(1+\frac{d_{N}\left(\sigma+\delta+d_{N}+\alpha\right)-\beta_{c c} \pi_{T}}{\left(d_{N} \alpha+\beta_{c c} \pi_{T}(2-\psi)\right)}(2-\psi)\right)\right] B \\
& -\left[\frac{d_{N}\left(\sigma+\delta+d_{N}+\alpha\right)-\beta_{c c} \pi_{T}}{\left(d_{N} \alpha+\beta_{c c} \pi_{T}(2-\psi)\right)}\left(\delta+d+d_{N}\right)\right. \\
& -\beta_{a a} \frac{\pi_{T}}{d_{N}}\left(1+\frac{d_{N}\left(\sigma+\delta+d_{N}+\alpha\right)-\beta_{c c} \pi_{T}}{\left(d_{N} \alpha+\beta_{c c} \pi_{T}(2-\psi)\right)}(2-\psi)\right) \\
& \left.-\delta_{1} \frac{\beta_{a a}\left(\left(\sigma+\delta+d_{N}+\alpha\right) \pi_{T}(2-\psi)+\alpha \pi_{T}\right)}{\left(\mu+d+d_{N}\right)\left(d_{N} \alpha+\beta_{c c} \pi_{T}(2-\psi)\right)}\right] A \\
& -\left[\frac{\beta_{a a}\left(\left(\sigma+\delta+d_{N}+\alpha\right) \pi_{T}(2-\psi)+\alpha \pi_{T}\right)}{\left(d_{N} \alpha+\beta_{c c} \pi_{T}(2-\psi)\right)}\right. \\
& \left.-\beta_{a a} \frac{\pi_{T}}{d_{N}}\left(1+\frac{d_{N}\left(\sigma+\delta+d_{N}+\alpha\right)-\beta_{c c} \pi_{T}}{d_{N} \alpha+\beta_{c c} \pi_{T}(2-\psi)}(2-\psi)\right)\right] I_{u} .
\end{aligned}
$$

Notice that

$$
\frac{\beta_{c c} \pi_{T}}{d_{N}}\left(1+\left(\frac{\left(d_{N}\left(\sigma+\delta+d_{N}+\alpha\right)-\beta_{c c} \pi_{T}\right)}{\left(d_{N} \alpha+\beta_{c c} \pi_{T}(2-\psi)\right)}\right)(2-\psi)\right)=\sigma+\delta+d_{N}+\alpha-\frac{\alpha\left(d_{N}\left(\sigma+\delta+d_{N}+\alpha\right)-\beta_{c c} \pi_{T}\right)}{\left(d_{N} \alpha+\beta_{c c} \pi_{T}(2-\psi)\right)}
$$

and

$$
\frac{\pi_{T}}{d_{N}}\left(1+\frac{d_{N}\left(\sigma+\delta+d_{N}+\alpha\right)-\beta_{c c} \pi_{T}}{d_{N} \alpha+\beta_{c c} \pi_{T}(2-\psi)}(2-\psi)\right)=\frac{\left(\sigma+\delta+d_{N}+\alpha\right)(2-\psi)+\alpha}{\left(d_{N} \alpha+\beta_{c c} \pi_{T}(2-\psi)\right)} \pi_{T} .
$$


It follows that

$$
\frac{d W}{d t} \leq-\frac{d_{N}\left(\delta+d+d_{N}\right)\left(\sigma+\delta+d_{N}+\alpha\right)}{d_{N} \alpha+\beta_{c c} \pi_{T}(2-\psi)}(1-\Theta) A
$$

where

$$
\begin{aligned}
\Theta & =\frac{\beta_{c c} \pi_{T}}{d_{N}\left(\sigma+\delta+d_{N}+\alpha\right)}+\frac{\beta_{a a} \pi_{T}(2-\psi)\left(\mu+d+d_{N}+\delta_{1}\right)}{d_{N}\left(\mu+d+d_{N}\right)\left(\delta+d+d_{N}\right)} \\
& +\frac{\alpha \beta_{a a} \pi_{T}\left(\mu+d+d_{N}+\delta_{1}\right)}{d_{N}\left(\mu+d+d_{N}\right)\left(\delta+d+d_{N}\right)\left(\sigma+\delta+d_{N}+\alpha\right)}
\end{aligned}
$$

Consequently $\dot{W}<0$ whenever $\Theta<1$. Furthermore, $\dot{W}=0$ implies that $(1-\Theta) A \leq 0$. It follows that $A=0$ and, thus, the fifth equation of system ([3.1) $)$ becomes

$$
\alpha B+S_{u}\left(\beta_{a a} I_{u}+\beta_{c a} B\right)+(1-\psi) S_{v}\left(\beta_{a a} I_{u}+\beta_{c a} B\right)=0
$$

Then $B=I_{u}=0$ and, consequently, $\{\dot{W}=0\} \subseteq\left\{A=B=I_{u}=0\right\}$. It follows that the maximum invariant set contained in $\{\dot{W}=0\}$ is the set $\left\{A=B=I_{u}=0\right\}$. Any solution start from the set $\left\{A=B=I_{u}=0\right\}$ must satisfies

$$
\left\{\begin{array}{l}
\frac{d T_{u}}{d t}=\pi_{T}-\left(d_{N}+\alpha\right) T_{u} \\
\frac{d S_{u}}{d t}=\alpha T_{u}-\left(p_{S} \varepsilon+d_{N}\right) S_{u} \\
\frac{d S_{v}}{d t}=p_{S} \varepsilon S_{u}-d_{N} S_{v}
\end{array}\right.
$$

It follows that

$$
\lim _{t \rightarrow \infty} T_{u}=\frac{\pi_{T}}{d_{N}+\alpha}, \lim _{t \rightarrow \infty} S_{u}=\frac{\alpha \pi_{T}}{\left(d_{N}+\alpha\right)\left(p_{S} \varepsilon+d_{N}\right)}, \text { and } \lim _{t \rightarrow \infty} S_{v}=\frac{\alpha \pi_{T} p_{S} \varepsilon}{\left(d_{N}+\alpha\right)\left(p_{S} \varepsilon+d_{N}\right) d_{N}} .
$$

Therefore, applying the LaSalle-Lyapunov Invariance Principal, it follows that $\bar{E}$ is globally stable.

\section{References}

[1] R. Ahmed and D. Gray Immunological memory and protective immunity: understanding their relation. Science. 272 (1996) 54-60.

[2] F. Amanat, F. Krammer, SARS-CoV-2 vaccines: status report. Immunity. 52(4) (2020) 583-589.

[3] R.M. Anderson, C. Vegvar, J. Truscot, B.S. Collyer, Challenges in creating herd immunity to SARS-CoV-2 infection by mass vaccination. Lancet Comment.; S0140-6736(20) (2020) 32318-32317.

[4] S.M . Bartsc, K.J. O'She, M.C. Ferguson, M.E. Bottazz, P.T. Wedlock, U. Strych, J.A. McKinnell, S.S. Siegmund, S.N. Cox, P.J. Hotez, B.Y. Lee, Vaccine efficacy needed for a 
medRxiv preprint doi: $h t t p s: / / d o i . o r g / 10.1101 / 2021.03 .14 .21253555$; this version posted March 17, 2021. The copyright holder for this preprint (which was not certified by peer review) is the author/funder, who has granted medRxiv a license to display the preprint in It is made available under a CC-BY-NC-ND 4.0 International license .

COVID-19 coronavirus vaccine to prevent or stop an epidemic as the sole Intervention. Am J Prev Med. 59(4) 2020 493-503.

[5] L. Benjamin, and V.R. William, Pediatrics August, 146 (2) e2020004879 (2020) doi: https://doi.org/10.1542/peds

[6] M. Boudjlal, A. Nehdi, I. Islam' Why do SARS-CoV vaccines not exist? The pharma scientific intelligence and business model must be revisited! Expert Opin Drug Discov. 15(11) (2020) 1233-1235.

[7] T. Britton, F. Ball and P. Trapman, A mathematical model reveals the influence of population heterogeneity on herd immunity to SARS-CoV-2, Science 369 (2020) 846849.

[8] K.A. Callow, H.F. M. Parry, , D.A. Tyrrell, The time course of the immune response to experimental coronavirus infection of man. Epidemiol Infect. 105(2) (1990) 435-46.

[9] J. Carrillo, N. Izquierdo-Useros, C. Avila-Nieto, E. Pradenas, B. Clotet, J. Blanco, Humoral immune responses and neutralizing antibodies againstSARS-CoV-2; implications in pathogenesis and protective immunity. Biochemical and Biophysical Research Communications, In Press (2021) https://doi.org/10.1016/j.bbrc.2020.10.108

[10] W.H. Chen, U. Strych , P.J. Hotez, M.E. Bottazzi, The SARS-CoV-2 vaccine pipeline: an overview. Curr Trop Med Rep. 7(2) (2020) 61-64.

[11] AS. Clem, Fundamentals of Vaccine Immunology. J Glob Infect Dis. 3(1) (2011) 73-78.

[12] J. Cohen, K. Kupferschmidt, As vaccines emerge, a global waiting game begins. Science. 370 (6523) (2020) 1385-1387.

[13] C. Conte, F. Sogni, P. Affanni, L. Veronesi, A. Argentiero, S. Esposito, Vaccines against coronavirus : the state of the art. Vaccines (Basel). 8(2) (2020) 309.

[14] J.M. J. Dan, , Y. Kato, K.M. Hastie, E.D. Yu, C.E. Faliti et al. Immunological memory to SARS-CoV-2 assessed for up to 8 months after infection. Science. (2021) eabf4063.DOI: 10.1126/science.abf4063.

[15] R.G. Douglas, V.B. Samant, The vaccine industry. Plotkin's Vaccines. 41-50.e1. (2018) doi:10.1016/B978-0-323-35761-6.00004-3.

[16] A.W.D. Edridge, J. Kaczorowska, A.C.R. Hoste et al. Seasonal coronavirus protective immunity is short-lasting. Nat Med. 26 (2020) 1691-1693. https://doi.org/10.1038/s41591-020-1083-1

[17] A. Enahoro Iboi, N. Calistus Ngonghala, B. Abba Gumel, Will an imperfect vaccine curtail the COVID-19 pandemic in the U.S.? Infect. Dis. Modell. 5 (2020) 510-524.

[18] G. Gabutti, E. d'Anchera, F. Sandri, M. Savio, A. Stefanati, Coronavirus: update related to the current outbreak of COVID-19. Infect. Dis. Ther. 9(2) 2020 241-253. 
medRxiv preprint doi: https://doi.org/10.1101/2021.03.14.21253555; this version posted March 17, 2021. The copyright holder for this preprint (which was not certified by peer review) is the author/funder, who has granted medRxiv a license to display the preprint in It is made available under a CC-BY-NC-ND 4.0 International license .

[19] A. Hammoumi, R. Qesmi, Impact assessment of containment measure against COVID-19 spread in Morocco, Chaos, Solit.Fractals. 140 (110231) (2020) 1-8. https://doi.org/10.1016/j.chaos.2020.110231.

[20] HCP of Morocco, https://www.hcp.ma/Population_r143.html (2020).

[21] S.H. Hodgson, K. Mansatta, G. Mallett, V. Harris, K.R.W. Emary, A.J. Pollard, What defines an efficacious COVID-19 vaccine? A review of the challenges assessing the clinical efficacy of vaccines against SARS-CoV-2. Lancet Infect Dis. (2020) DOI: https://doi.org/10.1016/S1473- 3099(20)30773-8.

[22] E.C. Holmes, Y.Z. Novel, 2019 coronavirus genome. 2020. http://virological.org/t/novel-2019-coronavirus-genome/319

[23] D.S. Hui, E.I. Azhar, Y.J. Kim, Z.A. Memish, M.d. Oh, A. Zumla, Middle East respiratory syndrome coronavirus: risk factors and determinants of primary, household, and nosocomial transmission. Lancet Infect Dis. 18 (2018) e217-27.

[24] E.A. Iboi, C.N. Ngonghala, A.B. Gumel, Will an imperfect vaccine curtail the COVID19 pandemic in the U.S.? Infect Dis Model. 5 (2020) 510-524.

[25] B. Isho, K.T. Abe, M Zuo, A.J. Jamal, B. Rathod et al. Persistence of serum and saliva antibody responses to SARS-CoV-2 spike antigens in COVID-19 patients. Science Immunology. 5(52) (2020) eabe5511.

[26] P. Jentsch, M. Anand, C.T. Bauch, Prioritising COVID-19 vaccination in changing social and epidemiological landscapes, medRxiv preprint (2020) (doi: https://doi.org/10.1101/2020.09.25.20201889).

[27] M. Jeyanathan, S. Afkhami, F. Smaill, M.S. Miller, Z. Xing, Immunological considerations for COVID-19 vaccine strategies. Nat Rev Immunol. 20 (2020) 615-632.

[28] J.H. Kim, F. Marks, J.D. Clemens, Looking beyond COVID-19 vaccine phase 3 trials. Nat Med. (2021) https://doi.org/10.1038/s41591-021-01230-y

[29] A.K. Kumar, Vaccine against Covid-19 disease - Present status of development. Indian J Pediatr. 87(10) (2020) 810-816.

[30] C. Lahariya, Vaccine epidemiology: A review. J Family Med Prim Care. 5(1) (2016) $7-15$.

[31] K. Leung, and J.T. Wu, The gradual release exit strategy after lockdown against COVID-19, The Lancet Regional Health-Western Pacific. (2020) https://doi.org/10.1016/j.lanwpc.2020.100008.

[32] A. Liénard and M.H. Chipart, Sur le signe de la partie relle des racines d'une équation algbrique. J. Math. Pures Appl. 10(6) (1914) 291-346. 
medRxiv preprint doi: https://doi.org/10.1101/2021.03.14.21253555; this version posted March 17, 2021. The copyright holder for this preprint (which was not certified by peer review) is the author/funder, who has granted medRxiv a license to display the preprint in It is made available under a CC-BY-NC-ND 4.0 International license .

[33] K. Macartney, H.E. Quinn, A.J. Pillsbury, A. Koirala, L. Deng, N. Winkler, A.L. Katelaris, M.V.N. O'Sullivan, C. Dalton, N. Wood and the NSW COVID19 Schools Study Team, Transmission of SARS-CoV-2 in Australian educational settings: a prospective cohort study. Lancet Child. Adolesc. Health. (2020) DOI: https://doi.org/10.1016/S2352-4642(20)30251-0.

[34] A. McDonnell, R. Van Exan, S. Lloyd, L. Subramanian, K. Chalkidou, A. La Porta et al. COVID-19 Vaccine Predictions: Using Mathematical Modelling and Expert Opinions to Estimate Timelines and Probabilities of Success of COVID-19 Vaccines [Internet]. Washington (DC): Center for Global Development; 2020 Oct 1 [cited 2020 Nov 5]. Available from: https://www.cgdev.org/ publication/covid-19-vaccinepredictions.

[35] Z.A. Memish, S. Perlman, M.D. Van Kerkhove, A. Zumla, Middle East respiratory syndrome. The Lancet. 395 (10229) (2020) 1063-1077.

[36] Z. Mukandavire, F. Nyabadza, N.J. Malunguza, D.F. Cuadros, T. Shiri, G. Musuka, Quantifying early COVID-19 outbreak transmission in South Africa and exploring vaccine efficacy scenarios. PLoS ONE 15(7): e0236003 (2020). https://doi. org/10.1371/journal.pone.0236003.

[37] A. Mullard, COVID-19 vaccine development pipeline gears up. World Report. 395(10239) (2020) 1751-1752.

[38] F. Ndariou, I. Area, J.J. Nieto, D.F. Torres, Mathematical modeling of COVID-19 transmission dynamics with a case study of Wuhan. (2020) Chaos Solitons Fractals, 10.1016/j.chaos.2020.109846.

[39] M. Nicola, Z. Alsafi, C. Sohrabi, A. Kerwan, A. Al-Jabir, C. Iosifidis, M. Agha, R. Agha, The socio-economic implications of the coronavirus pandemic (COVID-19): a review. Int J Surg. 78 (2020) 185-193.

[40] S.B. Omer, I. Yildirim, H.P. Forman, Herd Immunity and Implications for SARS-CoV-2 Control. JAMA Insights, Clinical Review \& Education. 324 (20) (2020) 2095-2096.

[41] A.D. Paltiel, J.L. Schwartz, A. Zheng, R.P. Walensky, Clinical outcomes of a COVID-19 Vaccine: implementation over efficacy. Health Affairs. 40 (1) (2021) 42-52.

[42] E. Padron-Regalado, Vaccines for SARS-CoV-2: lessons from others S.H. Hodgson, K. Mansatta, G. Mallett, V. Harris, K.R.W. Emary, A.J. Pollard, What defines an efficacious COVID-19 vaccine? A review of the challenges assessing the clinical efficacy of vaccines against SARS-CoV-2. Lancet Infect Dis. 2020; DOI: https://doi.org/10.1016/S1473- 3099(20)30773-8. coronavirus strains. Infect Dis Ther. $9(2)(2020) 255-274$.

[43] J.S.M. Peiris, Y. Guan Y, K.Y. Yuen, Severe acute respiratory syndrome. Nat Med. 10(Suppl 12) (2004) 88-97. 
medRxiv preprint doi: https://doi.org/10.1101/2021.03.14.21253555; this version posted March 17, 2021. The copyright holder for this preprint (which was not certified by peer review) is the author/funder, who has granted medRxiv a license to display the preprint in It is made available under a CC-BY-NC-ND 4.0 International license .

[44] L.B. Rodda, J. Netland, L. Shehata, K.B. Pruner, P.A. Morawski et al. Functional SARS-CoV-2-specific immune memory persists after mild COVID-19. Cell 184(1) (2021) 169-183.e17.

[45] S.F. Sallusto, A. Lanzavecchia, K. Araki, R. Ahmed, From Vaccines to Memory and Back. Immunity. 33(4) (2010) 451-463.

[46] R.A. Strikas, A.C. Mawle, L.K. Pickering, W.A. Orenstein, Active Immunization. Principles and Practice of Pediatric Infectious Diseases. e4 (2018) 43-71.

[47] T. Thanh Le, Z. Andreadakis, A. Kumar, R. Gómez Román, S. Tollefsen, M. Saville, S. Mayhew, The COVID-19 vaccine development landscape. Nat Rev Drug Discov. 19(5) (2020) 305-306.

[48] The Ministry of Health of Morocco, The Official Coronavirus Portal of Morocco. www.covidmaroc.ma (2020).

[49] The Ministry of Interior of Morocco. https://www.mapnews.ma/fr/actualites/social/campagnede-vaccination-anti-covid-19-mode-op\%C3\%A9ratoire. December 16, (2020).

[50] L.V. Tse, R.M. Meganck, R.L. Graham, R.S. Baric, The current and future state of vaccines, antivirals and genes therapies against emerging coronavirus. Front Microbiol. 11: 658 (2020). doi: 10.3389/fmicb.2020.00658.

[51] P. Van den Driessche, J. Watmough J., Reproduction numbers and subthreshold endemic equilibria for compartmental models of disease transmission, Mathematical Biosciences 180 (2002) 29-48.

[52] D. van Riel, de E. Wit, Next-generation vaccine platforms for COVID-19. Nat Mater. 19(8) (2020) 810-812.

[53] A. Vespignani, H. Tian, C. Dye et al. Modelling COVID-19. Nat Rev Phys 2 (2020) 279-281, https://doi.org/10.1038/s42254-020-0178-4.

[54] A. Wajnberg, F. Amanat, A. Firpo, D.R. Altman, M.J. Bailey et al. Robust neutralizing antibodies to SARS-CoV-2 infection persist for months. Science. 370 (2020) 1227-1230.

[55] H. Wang, X. Li, T. Li, S. Zhang, L. Wang, X. Wu, J. Liu, The genetic, origin, and diagnosis of SARS-CoV-2. Eur J Clin Microbiol Infect Dis. 39(9) (2020) 1629-1635.

[56] N. Wang, J. Shang, S. Jiang, L. Du, Subunit vaccines against emerging pathogenic human coronaviruses. Front Microbiol. 11: 298 (2020). doi:10.3389/fmicb.2020.00298

[57] WHO, Modes of transmission of virus causing COVID-19: implications for ICP precaution recommendations (2020). Available from: https://apps.who.int/iris/bitstream/handle/10665/331601/WHO-2019-nCoVSci_Brief-Transmission_modes-2020.1-eng.pdf. 
medRxiv preprint doi: https://doi.org/10.1101/2021.03.14.21253555; this version posted March 17, 2021. The copyright holder for this preprint (which was not certified by peer review) is the author/funder, who has granted medRxiv a license to display the preprint in It is made available under a CC-BY-NC-ND 4.0 International license .

[58] WHO, News briefing on 24th February 2020; [updated 2020 February 24; cited 2020 February 24]. Available from: https://www.who.int/dg/speeches/detail/who-directorgeneral-s-opening-remarks-at-the-media-briefing-on-covid-19-24-february-2020.

[59] WHO, The access to COVID-19 tools (ACT) accelerator. 2020. Available from: https://www.who.int/initiatives/act-accelerator

[60] WHO, The push for a COVID-19 vaccine. 2020. Available from: https://www.who.int/emergencies/diseases/novel-coronavirus-2019/covid-19-vaccines.

[61] WHO, More than 150 countries engaged in COVID-19 vaccine global access facility. 2020. Available from: https://www.who.int/news/item/15-07-2020-more-than-150countries-engaged-in-covid-19-vaccine-global-access-facility.

[62] WHO. Coronavirus disease (COVID-19): Herd immunity, lockdowns and COVID-19. Updated 31 December (2020).

[63] Z.W. Ye, S. Yuan, K.S. Yuen, S.Y. Fung, C.P. Chan, D.Y. Jin, Zoonotic origins of human coronaviruses. Int J Biol Sci. 16(10) (2020) 1686-1697.

[64] J. Zhang, H. Zeng, J. Gu, H. Li, L. Zheng, Q. Zou, Progress and prospects on vaccine development against SARS-CoV-2. Vaccines (Basel). 8 (2) ( 2020) 153. 